\title{
Magnetic Mixed Micelles Composed of a Non-Ionic Surfactant and Nitroxide Radicals Containing a D-Glucosamine Unit: Preparation, Stability, and Biomedical Application
}

\author{
Kota Nagura ${ }^{1,+}+\mathbb{D}$, Yusa Takemoto ${ }^{1,+}{ }^{+}$Fumi Yoshino ${ }^{2}$, Alexey Bogdanov ${ }^{3}$, Natalia Chumakova ${ }^{3}$, \\ Andrey Kh. Vorobiev ${ }^{3}$ (D), Hirohiko Imai ${ }^{4}$, Tetsuya Matsuda ${ }^{4}$ (D), Satoshi Shimono ${ }^{1}$ (D), \\ Tatsuhisa Kato ${ }^{1}$, Naoki Komatsu ${ }^{1, *(D)}$ and Rui Tamura ${ }^{1, *}$ \\ 1 Graduate School of Human and Environmental Studies, Kyoto University, Kyoto 606-8501, Japan; \\ k.nagura1005@gmail.com (K.N.); vahadrr@gmail.com (Y.T.); shimono.satoshi.4r@kyoto-u.ac.jp (S.S.); \\ kato.tatsuhisa.6e@kyoto-u.ac.jp (T.K.) \\ 2 Department of Obstetrics and Gynecology, Shiga University of Medical Science, Shiga 520-2192, Japan; \\ iwamatsu@belle.shiga-med.ac.jp \\ 3 Department of Chemistry, M.V. Lomonosov Moscow State University, Moscow 119991, Russian Federation; \\ avbgdn@gmail.com (A.B.); harmonic2011@yandex.ru (N.C.); a.kh.vorobiev@gmail.com (A.K.V.) \\ 4 Graduate School of Informatics, Kyoto University, Kyoto 606-8501, Japan; imai@sys.i.kyoto-u.ac.jp (H.I.); \\ tetsu@i.kyoto-u.ac.jp (T.M.) \\ * $\quad$ Correspondence: komatsu.naoki.7w@kyoto-u.ac.jp (N.K.); tamura.rui.45x@st.kyoto-u.ac.jp (R.T.); \\ Tel.: +81-75-753-6833 (N.K.); +81-77-577-1337 (R.T.) \\ + These authors should be addressed as co-first author.
}

Received: 5 December 2018; Accepted: 9 January 2019; Published: 19 January 2019

\begin{abstract}
Metal-free magnetic mixed micelles (mean diameter: $<20 \mathrm{~nm}$ ) were prepared by mixing the biocompatible non-ionic surfactant Tween 80 and the non-toxic, hydrophobic pyrrolidine- $N$-oxyl radicals bearing a D-glucosamine unit in $\mathrm{pH} 7.4$ phosphate-buffered saline (PBS). The time-course stability and in vitro magnetic resonance imaging (MRI) contrast ability of the mixed micelles was found to depend on the length of the alkyl chain in the nitroxide radicals. It was also confirmed that the mixed micelles exhibited no toxicity in vivo and in vitro and high stability in the presence of a large excess of ascorbic acid. The in vivo MRI experiment revealed that one of these mixed micelles showed much higher contrast enhancement in the proton longitudinal relaxation time $\left(T_{1}\right)$ weighted images than other magnetic mixed micelles that we have reported previously. Thus, the magnetic mixed micelles presented here are expected to serve as a promising contrast agent for theranostic nanomedicines, such as MRI-visible targeted drug delivery carriers.
\end{abstract}

Keywords: nitroxide radical; magnetic resonance imaging; glucosamine; cancer; micelle

\section{Introduction}

Non-invasive imaging of living tissue is of great importance in the medical field. The magnetic resonance imaging (MRI) method is one of the most frequently used and important imaging techniques in clinical medicine. In fact, the use of MRI contrast agents plays a crucial role in accurately evaluating physiological and pathological changes. The majority of MRI contrast agents approved by the US Food and Drug Administration (FDA) are gadolinium-based contrast agents (GBCAs) such as Magnevist (a GdIII complex agent) [1-3]. Although they are used on a daily basis, this modality still faces many challenges [4-8]. For example, people with moderate to advanced kidney failure are in danger of 
developing nephrogenic systemic fibrosis through the use of GBCAs. Thus, it is urgently required to exploit novel agents that exhibit adequate contrast enhancement with a very low risk.

Metal-free magnetic nanoparticles containing nitroxide radicals as a spin source have attracted great interest since the 1980s [9] because of their lack of toxicity, despite the imaging ability being less compared to $\mathrm{Gd}^{\mathrm{III}}$ complex agents [10] and their having less reduction resistance to antioxidants such as ascorbic acid and glutathione [11]. However, the reduction resistance should potentially improve through the molecular design and/or the micelle construction of nitroxide radicals [12-17]. In this context, we have recently prepared metal-free magnetic mixed micelles comprised of a surfactant, Brij 58 (1) or Tweens 80 (2), and pyrrolidine- $N$-oxyl radical 3, namely $1 / 3$ or $2 / 3$ (Figure 1 ), according to a simple experimental procedure $[18,19]$. These micelles showed high colloidal stability, reduction resistance to ascorbic acid, and contrast enhancement in the $T_{1}$-weighted MRI in phosphate-buffered saline (PBS) in vitro and in vivo. The mixed micelle $2 / 3$ was found to be much less toxic than $1 / 3$. Furthermore, additional hydrophobic fluorophores or drugs were stably encapsulated inside the mixed micelles. Although passive targeting can be expected due to the micelle size (10-20 nm), the micelles that we prepared did not possess any active targeting site for tumor.

Herein, we report on the novel metal-free mixed micelles including nitroxide radicals $4_{n}$ conjugated with a D-glucosamine unit as a tumor targeting site, because D-glucosamine derivatives are well-known to accumulate in tumor cells [20-23]. The obtained magnetic mixed micelles showed little toxicity, excellent in vitro MRI contrast ability, and high stability in the presence of an excess amount of ascorbic acid. When applied to in vivo imaging for healthy mice, bright MRI contrast enhancement was observed in the liver.

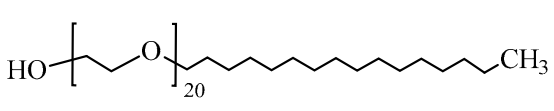

1

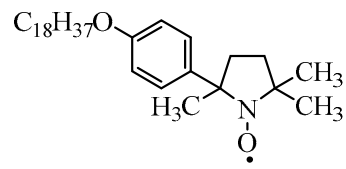

3
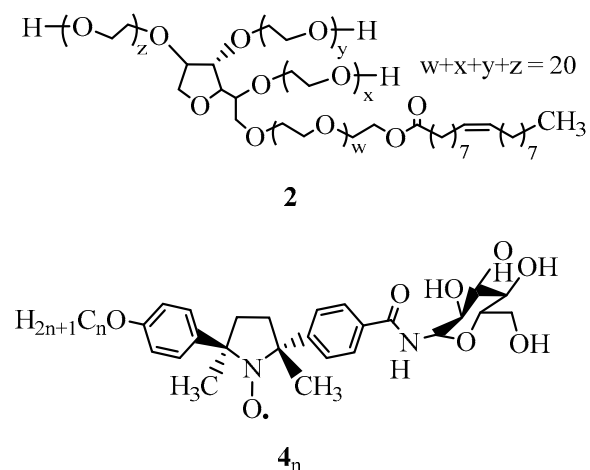

Figure 1. Molecular structures of non-ionic surfactants Brij 58 (1) and Tween 80 (2), and nitroxide radicals 3 and $4_{\mathrm{n}}\left(n=14,16\right.$, and 18). Compounds $4_{\mathrm{n}}$ are a ca. 1:1 mixture of D- $(R, R)$ and $\mathrm{D}-(S, S)$ diastereomers, see the Supporting Information for the synthesis and characterization.

\section{Results and Discussion}

\subsection{Preparation, Stability and In Vitro MRI Contrast Ability of $\mathbf{2} / \mathbf{4}_{\mathrm{n}}$}

The nitroxide radicals $4_{n}(n=14,16$, and 18 in Figure 1, Figures S1 and S2) were synthesized by condensation of the racemic benzoic acid derivatives of the nitroxide radicals (a 1:1 mixture of $(R, R)$ and $(S, S)$ enantiomers) [24,25] and D-tetraacetylglucosamine [26-28], followed by deacetylation (Schemes S1 and S2 in the Supplementary Information).

The mixed micelles $2 / 4_{n}$ (Figure 1 ) were prepared at a concentration of $10 \mathrm{mM}$ for each component in the PBS according to the procedure described in the Supplementary Information. The stability of the micelles was found to depend on the length of the alkyl chain $(n=14,16$, and 18) in the radicals $\mathbf{4}_{\mathrm{n}}$ (Table 1 and Figure 2). The $\mathbf{2} / \mathbf{4}_{16}$ and $\mathbf{2} / \mathbf{4}_{18}$ were formed as a clear dispersion immediately after preparation and their mean diameter gradually increased up to 92 and $45 \mathrm{~nm}$ after one week, respectively (Table 1 ). The micelle $2 / \mathbf{4}_{14}$ collapsed within one day to give white precipitates of $\mathbf{4}_{14}$ after $24 \mathrm{~h}$. From these results, summarized in Table 1, the relative stability of the micelles $2 / \mathbf{4}_{\mathrm{n}}$ in PBS 
was in the following order: $2 / \mathbf{4}_{18}>\mathbf{2} / \mathbf{4}_{16}>\mathbf{2} / \mathbf{4}_{14}$. The similar dependence of the micellar stability on the alkyl chain length in the nitroxide radicals $4_{n}$ was also observed in the cases of the mixed micelles $\mathbf{1} / \mathbf{3}$ and $\mathbf{2 / 3}[18,19]$. The mean diameters of the resulting magnetic mixed micelles $\mathbf{2} / \mathbf{4}_{\mathrm{n}}$ in PBS were determined to be 13 to $16 \mathrm{~nm}$ by DLS analysis (Table 1 and Figure 2). Their mean diameters fell in a range of 10-100 $\mathrm{nm}$, which is required for the most prolonged blood circulation time.

Importantly, the once-precipitated sample of $\mathbf{2} / \mathbf{4}_{14}$ was revived to the original clear dispersion with the same diameter $(16 \mathrm{~nm})$ by just heating it with full reproducibility (Table 1 ). The micelle $\mathbf{2} / \mathbf{4}_{14}$ turned out to be easily available as a clear dispersion even after the long-term preservation of the precipitated sample.

Table 1. Mean diameters and colloidal stability of the mixed micelles $2 / \mathbf{4}_{\mathrm{n}}(n=14,16$, and 18$)$ in phosphate-buffered saline (PBS) at $30{ }^{\circ} \mathrm{C}$.

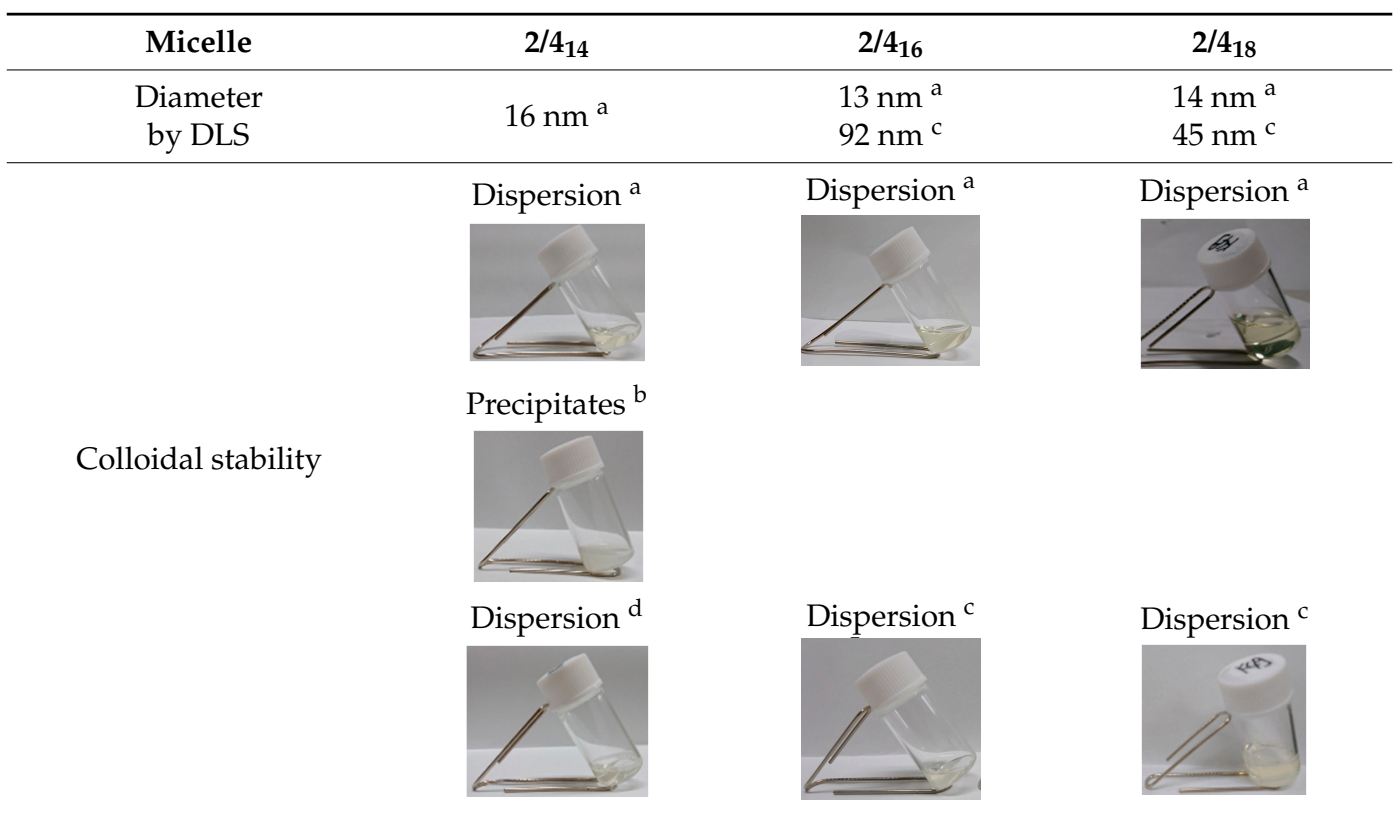

a Immediately after preparation. ${ }^{\mathrm{b}}$ After $24 \mathrm{~h}$ of preparation. ${ }^{\mathrm{c}}$ After 6 days of preparation. ${ }^{\mathrm{d}}$ After heating the precipitates.

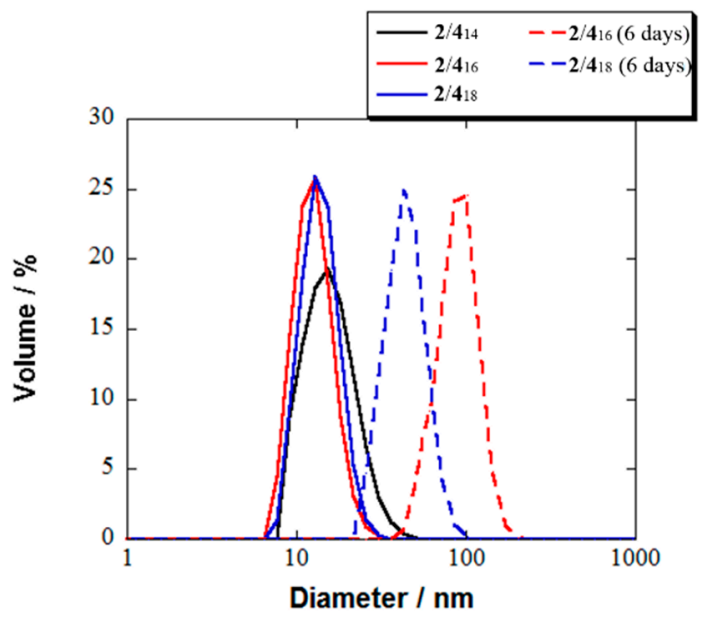

Figure 2. Mean diameters of mixed micelles $2 / 4_{n}\left(n=14,16\right.$, and 18) determined by DLS at $25{ }^{\circ} \mathrm{C}$ in PBS (black solid line: $\mathbf{2} / \mathbf{4}_{14}$ just after preparation, red solid line: $\mathbf{2} / \mathbf{4}_{16}$ just after preparation, blue

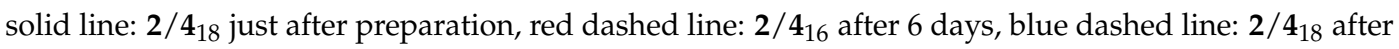
6 days). See the Supplementary Information for experimental details. 
The dependence of the alkyl chain length in $\mathbf{4}_{\mathrm{n}}$ on the longitudinal relaxivity $\left(r_{1}\right)$ of $2 / \mathbf{4}_{\mathrm{n}}$ was determined from the relaxation time $\left(T_{1}\right)$ as a function of the concentration at $25^{\circ} \mathrm{C}$ by using an MRI machine at 7.0 T. Sufficiently bright $T_{1}$-weighted MR phantom images were obtained at a concentration of $10 \mathrm{mM}$ of the magnetic mixed micelles $\mathbf{2} / \mathbf{4}_{14}, \mathbf{2} / \mathbf{4}_{16}$, and $\mathbf{2} / \mathbf{4}_{18}$ as compared with that of the control PBS (panel A, E, and I in Figure 3a). This result implies that $2 / \mathbf{4}_{\mathrm{n}}$ may show a distinct MRI contrast enhancement in vivo in this concentration or higher. The linear regression analysis yielded $r_{1}=0.14$, 0.13 , and $0.11 \mathrm{mM}^{-1} \mathrm{~s}^{-1}$ for $\mathbf{2} / \mathbf{4}_{14}, \mathbf{2} / \mathbf{4}_{16}$ and $\mathbf{2} / \mathbf{4}_{18}$, respectively (Figure $3 \mathrm{~b}$ ). That is, the MRI contrast ability of the micelle $2 / \mathbf{4}_{\mathrm{n}}$ in PBS was in the following order: $\mathbf{2} / \mathbf{4}_{14}>\mathbf{2} / \mathbf{4}_{16}>\mathbf{2} / \mathbf{4}_{18}$. The mixed micelle $2 / 4_{14}$ was used for further experiments for the following two reasons: (1) $2 / \mathbf{4}_{14}$ exhibited superior in vitro MRI-enhanced ability to those of $\mathbf{2} / \mathbf{4}_{16}$ and $\mathbf{2} / \mathbf{4}_{18}$, and (2) the clear dispersion was fully revived in a reproducible manner by simply heating the precipitated sample. Although the stability of the

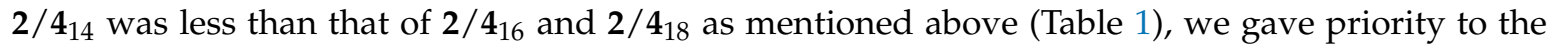
MRI-enhanced ability over the stability.

(a)

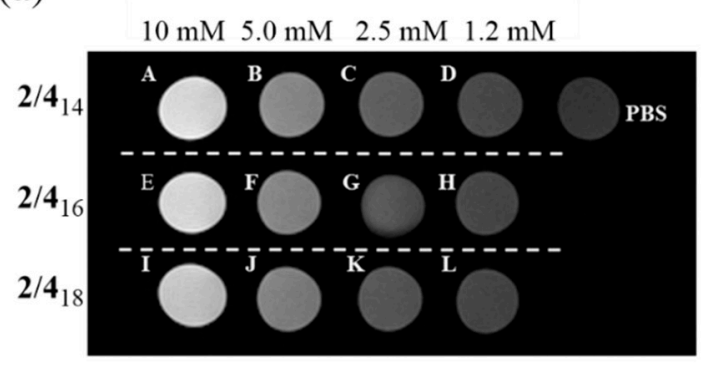

(b)

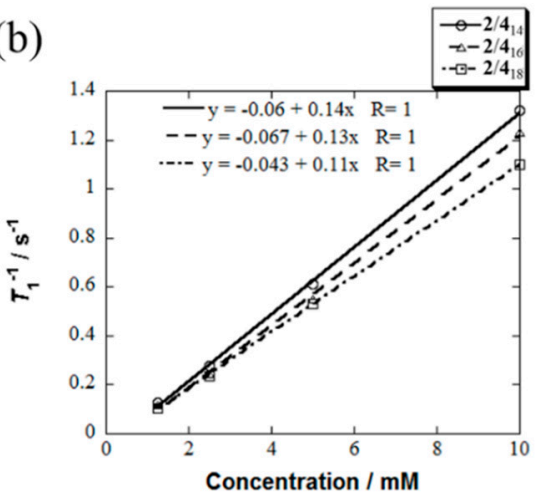

Figure 3. (a) (A-D) $T_{1}$-weighted MRI phantom images of $\mathbf{2} / \mathbf{4}_{14}\left(\mathbf{4}_{14}: 1.2\right.$ to $\left.10 \mathrm{mM}\right),(\mathrm{E}-\mathrm{H}) \mathbf{2} / \mathbf{4}_{16}\left(\mathbf{4}_{16}\right.$ : 1.2 to $10 \mathrm{mM}$ ) and (I-L) $2 / \mathbf{4}_{18}\left(\mathbf{4}_{18}: 1.2\right.$ to $10 \mathrm{mM}$ ) in PBS, and control PBS at $7.0 \mathrm{~T}$ and $25^{\circ} \mathrm{C}$. (b) Plots of $T_{1}{ }^{-1}$ vs concentrations of $\mathbf{2} / \mathbf{4}_{14}$ (solid line), $\mathbf{2} / \mathbf{4}_{16}$ (dashed line) and $\mathbf{2} / \mathbf{4}_{18}$ (dashed and dotted line) at 1.2, 2.5, 5.0, $10 \mathrm{mM}$ for each component. The $r_{1}$ was determined from the slope of each line. See the Supplementary Information for experimental details.

Table 2. The effective activation energy of the rotation diffusion of $4_{14}$ in $2 / 4_{14}$ and 3 in $2 / 3$.

\begin{tabular}{cc}
\hline Mixed Micelle & $E^{a}{ }_{z} / \mathbf{k J m o l}^{-\mathbf{1}}$ \\
\hline $\mathbf{2} / \mathbf{4}_{14}$ & $21.1 \pm 1.0$ \\
$\mathbf{2} / \mathbf{3}^{\mathrm{a}}$ & $18.4 \pm 0.4$ \\
\hline
\end{tabular}

a Previously reported value [19].

These $r_{1}$ values were much larger than those of micelles $\mathbf{2} / \mathbf{3}$ and $\mathbf{1} / \mathbf{3}\left(r_{1}=0.07\right.$, and $0.09 \mathrm{mM}^{-1} \mathrm{~s}^{-1}$, respectively, at 7.0 T), which we reported previously, although they were much lower than those of $\mathrm{Gd}^{\mathrm{III}}$ complex agents [6]. These experimental results could be interpreted in terms of the slower rotation diffusion of $\mathbf{4}_{14}$ than that of 3 inside the mixed micelles [29-31]. In order to compare the rotation diffusion mobility between radicals $4_{14}$ and 3 inside the micelles, the electron paramagnetic resonance (EPR) spectra of radical $4_{14}$ or 3 in the micelles consisting of a 1:0.01 molar ratio of surfactant 2 and $\mathbf{4}_{14}$ or 3 were measured in the temperature range $263-298 \mathrm{~K}$ and then were numerically simulated as described in the Supplementary Information (Figure 4 and Figure S3, and Table S1). The temperature dependence of the rotation diffusion mobility was successfully described by Arrhenius law with the values of activation energy $\left(E^{a} z\right)$ shown in Table 2, indicating that $\mathbf{4}_{14}$ showed slower rotational diffusion inside the micelle to produce a highly enhanced MRI compared to 3 . The better $r_{1}$ of $\mathbf{2} / \mathbf{4}_{14}$ than $2 / \mathbf{4}_{16}$ and $2 / \mathbf{4}_{18}$ mentioned above might be interpreted by the slower rotation diffusion mobility of $\mathbf{4}_{14}$ than $\mathbf{4}_{16}$ and $\mathbf{4}_{18}$. 


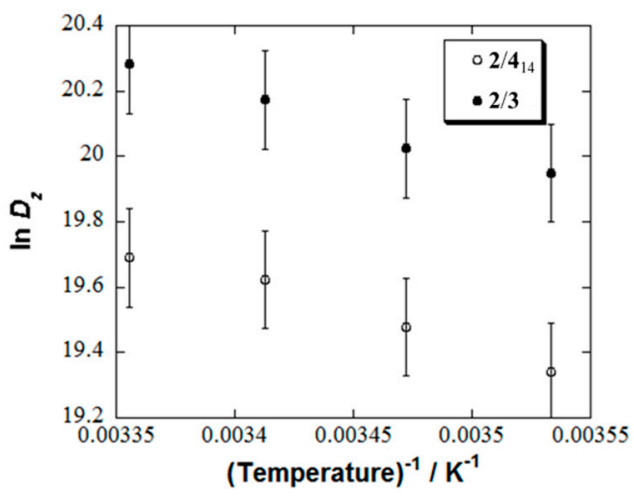

Figure 4. Temperature dependence of rotation diffusion coefficient $D_{z}$ of $4_{14}$ in $2 / 4_{14}$ and 3 in $2 / 3$. The data of $2 / 3$ was cited from reference 19 . See the Supplementary Information for experimental details of $2 / 4_{14}$.

\subsection{Reduction Resistivity of $\mathbf{2} / \mathbf{4}_{14}$ in the Presence of Ascorbic Acid}

The concentration of ascorbic acid in the healthy adult serum was reported to be kept in the range of 14.9-52.8 $\mu \mathrm{M}$ by a daily intake of ascorbic acid $(60 \mathrm{mg})$ [32]. When nitroxide radicals were applied to the in vivo MRI measurement, radical reduction occurred and resulted in a significant decrease in the MRI contrast [33-35]. For example, 2,2,6,6-tetramethylpiperidine- $N$-oxyl (TEMPO) derivatives, such as 4-oxo-2,2,6,6-tetramethylpiperidine- $N$-oxyl (TEMPONE) and 4-hydroxy-2,2,6,6-tetramethylpiperidine- $N$-oxyl (TEMPOL), were reduced rapidly (half-life $\left(\tau_{1 / 2}\right)$ $<2 \mathrm{~min}$ ) to the corresponding hydroxylamines in the presence of ascorbic acid [36]. In our molecular design, we expected that the interplay between four long hydrophilic tails in $\mathbf{2}$ and four neighboring substituents in $\mathbf{4}_{14}$ should enhance the reduction resistance to ascorbic acid sterically. The decay of $\mathbf{4}_{14}$ in $2 / \mathbf{4}_{14}$ in response to a large excess of ascorbic acid (20 equiv based on $\mathbf{4}_{14}$ ) in PBS was monitored by EPR spectroscopy (Figure 5). As expected, the $\tau_{1 / 2}$ of $2 / 4_{14}$ (30 $\mathrm{min}$ ) was almost comparable to that of $\mathbf{2} / \mathbf{3}$ (33 $\mathrm{min})$ and much longer than that of $\mathbf{1} / \mathbf{3}(7 \mathrm{~min})$ [19].

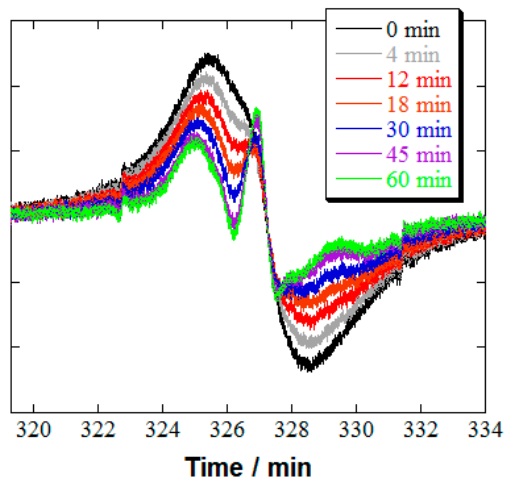

(a)

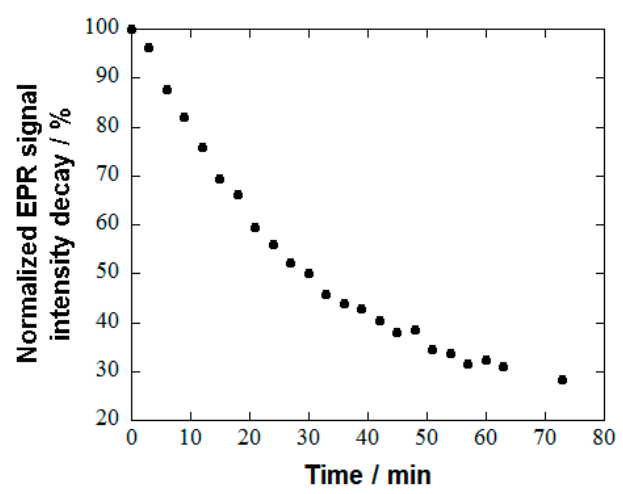

(b)

Figure 5. (a) Time-course of EPR spectra and (b) the reduction resistance of $\mathbf{4}_{14}$ in $\mathbf{2} / \mathbf{4}_{14}$ to a large excess of ascorbic acid (20 equiv based on $4_{14}$ ) in PBS at $25^{\circ} \mathrm{C}$. The normalized signal intensity decay was evaluated by a double-integration method. See the Supplementary Information for experimental details.

\subsection{Biomedical Application of $\mathbf{2} / \mathbf{4}_{14}$}

Since biocompatibility is a prerequisite of using the magnetic mixed micelles as an MRI contrast agent, the cancer cell viability of $2 / 4_{14}$ was assessed by the CCK-8 assay at the initial concentration of $2.5 \mathrm{mM}$ for $\mathbf{2}$ and $\mathbf{4}_{14}$ and compared with those of pure micelle of $\mathbf{2}$, designated as P2, (Figure 6a). Both P2 and $\mathbf{2} / \mathbf{4}_{14}$ exhibited little cytotoxicity to HeLa cells at concentrations up to $2.5 \mathrm{mM}$, demonstrating that $\mathbf{2} / \mathbf{4}_{14}$ is an appropriate candidate for in vivo experiment. In addition, 
the body weights gradually increased in the healthy Institute of Cancer Research (ICR) mice over one month after injection of $\mathbf{2 / 4} 14,2 / 3$ and PBS (Figure $6 \mathrm{~b}$ ). It was concluded that mixed micelles $2 / \mathbf{4}_{14}$ can serve as a bio-compatible MRI contrast agent similar to $2 / 3$.

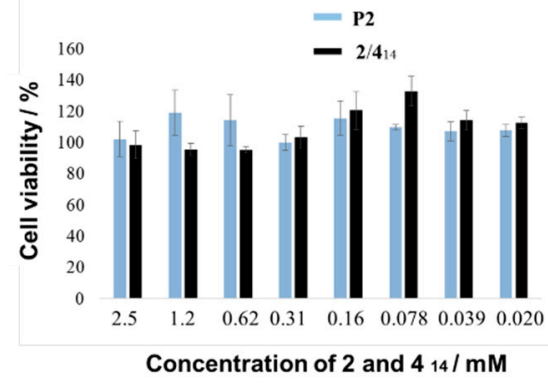

(a)

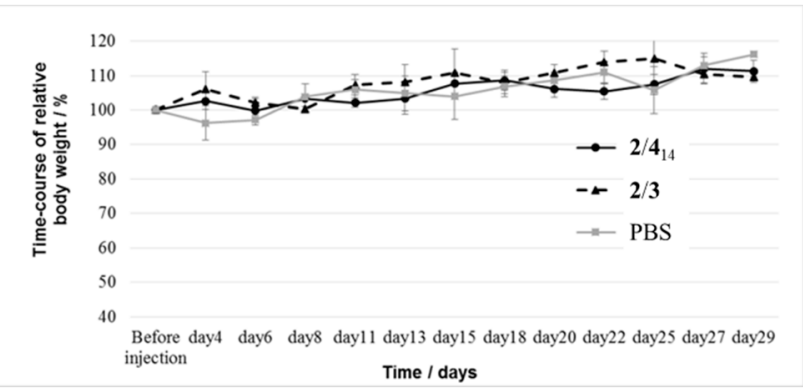

(b)

Figure 6. (a) In vitro cell viability of $\mathbf{2} / \mathbf{4}_{14}$ and $\mathbf{P 2}$ by using the CCK-8 kit after incubation for $24 \mathrm{~h}$ at $37^{\circ} \mathrm{C}$ under $5 \% \mathrm{CO}_{2}$ and (b) in vivo toxicity of $\mathbf{2} / \mathbf{4}_{14}$ for healthy ICR mice weight (three mice for each of $2 / 4_{14}, 2 / 3$ and control PBS) as a function of time after injection of $200 \mu \mathrm{L}$ of mixed micelles ( $40 \mathrm{mM}$ for each component) in PBS or PBS. See the Supplementary Information for experimental details.

Finally, the in vivo MRI experiment using $2 / \mathbf{4}_{14}$ was performed for healthy ICR mice. Bright MRI contrast enhancement was observed in the liver in both coronal and sagittal planes over $1 \mathrm{~h}$ with high reproducibility (Figure 7 ). This result reveals that the magnetic mixed micelle $\mathbf{2 / 4} \mathbf{4}_{14}$ is effective as an in vivo $T_{1}$-weighted MRI contrast agent. The prolonged MRI enhancement observed for $\mathbf{2} / \mathbf{4}_{14}$ is attributed to the high resistance to reducing agents as described above.
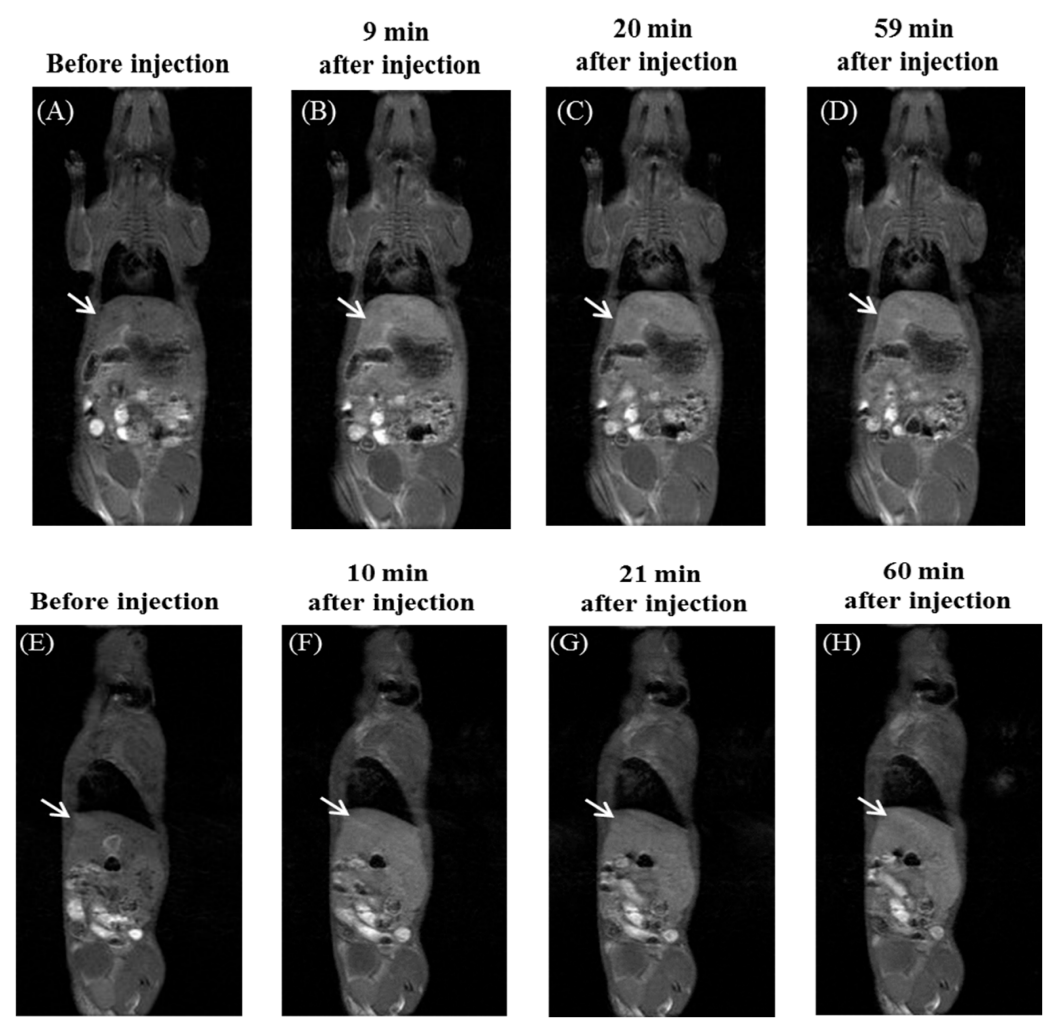

Figure 7. Time-course of coronal (panels A-D) and sagittal (panels E-H) $T_{1}$-weighted MR images of an ICR mouse before and after injection of $200 \mu \mathrm{L}$ of $\mathbf{2} / \mathbf{4}_{14}(40 \mathrm{mM})$ in PBS. Distinct contrast enhancement was observed in the liver of the mouse (indicated by white arrows). See the Supplementary Information for experimental details. 


\section{Conclusions}

We prepared highly robust and biocompatible metal-free magnetic mixed micelles which are composed of non-ionic surfactant 2 and hydrophobic nitroxide radical $4_{n}$ in PBS. The time-course stability and in vitro MRI contrast ability of the mixed micelles was found to depend on the length $(n)$ of the alkyl chain in the nitroxide radicals. In addition, the mixed micelle $2 / \mathbf{4}_{14}$ showed a considerable reduction resistance to a large excess of ascorbic acid, little toxicity, and sufficient contrast enhancement in the $T_{1}$-weighted MRI in vivo. Such highly biocompatible magnetic mixed micelles composed of nitroxide radicals bearing a D-glucosamine unit are expected to be utilized as a low-molecular-weight cancer targeted MRI contrast agent in line with the theranostic applications of micelles, which have recently been attracting increasing interest [37-39].

Supplementary Materials: The following are available online at http:/ / www.mdpi.com/1999-4923/11/1/42/s1, Scheme S1: Synthesis of $7_{\mathrm{n}}\left(n=14,16\right.$, and 18); Scheme S2: Synthesis of $4_{\mathrm{n}}(n=14,16$, and 18); Figure S1: FT-IR spectra (KBr) of (a) $\mathbf{4}_{14}$ (b) $\mathbf{4}_{16}$ and (c) $\mathbf{4}_{18}$; Figure S2: HPLC charts of (a) $\mathbf{4}_{14}$, (b) $\mathbf{4}_{16}$, and (c) $\mathbf{4}_{18}$; Figure S3: Representative EPR spectra of $\mathbf{2} / \mathbf{4}_{14}$ (a molar ratio of 1:0.01) and the results of their computer simulation at high temperatures; Table S1: Rotation diffusion coefficients and the angles determining the position of the main rotation axis in $g$-tensor frame for radical $\mathbf{4}_{14}$ in $\mathbf{2 / 4}$ (a molar ratio of 1:0.01).

Author Contributions: Conceptualization, K.N. and Y.T.; Methodology, K.N., Y.T., F.Y., A.B., N.C., A.K.V., H.I. and T.M.; Software, A.B., N.C., A.K.V. and T.K.; Validation, K.N.; Investigation, K.N. and Y.T.; Resources, N.K. and R.T.; Data Curation, K.N., Y.T., F.Y., H.I. and S.S.; Writing-Original Draft Preparation, K.N.; Writing-Review and Editing, N.K. and R.T.; Supervision, N.K. and R.T.; Project Administration, N.K. and R.T.; Funding Acquisition, A.K.V., N.K. and R.T.

Funding: The present work was supported by JSPS KAKENHI (Grant numbers 26248024 and 26286003), the Japan-Russia bilateral collaboration program and the Russian Foundation for Basic Research (RFBR) (Grant number 16-33-60139 mol_a_dk).

Acknowledgments: Tween 80 was kindly supplied by DKS Co. Ltd. The MRI experiments of this work were performed in the Division for Small Animal MR, Medical Research Support Center, Graduate School of Medicine, Kyoto University, Japan.

Conflicts of Interest: The authors declare no conflict of interest.

\section{References}

1. Molecular Imaging and Contrast Agent Database (MICAD) Internet, Bethesda (MD), National Center for Biotechnology Information (US), 2004-2013. Available online: http:/ / www.ncbi.nlm.nih.gov / books / NBK5330 / (accessed on 1 March 2018).

2. Malayeri, A.A.; Brooks, K.; Bryant, L.H.; Evers, R.; Kumar, P.; Reich, D.S.; Bluemke, D.A. NIH perspective on reports of gadolinium deposition in the brain. J. Am. Coll. Radiol. 2016, 13, 237-241. [CrossRef] [PubMed]

3. Gale, E.M.; Caravan, P.; Rao, A.G.; McDonald, R.J.; Winfeld, M.; Fleck, R.J.; Gee, M.S. Gadolinium-based contrast agents in pediatric magnetic resonance imaging. Pediatr. Radiol. 2017, 47, 507-521. [CrossRef] [PubMed]

4. Radbruch, A.; Weberling, L.D.; Kieslich, P.J.; Eidel, O.; Burth, S.; Kickingereder, P.; Heiland, S.; Wick, W.; Schlemmer, H.P.; Bendszus, M. Gadolinium retention in the dentate nucleus and globus pallidus is dependent on the class of contrast agent. Radiology 2015, 275, 783-791. [CrossRef] [PubMed]

5. Kanda, T.; Fukusato, T.; Matsuda, M.; Toyoda, K.; Oba, H.; Kotoku, J.; Haruyama, T.; Kitajima, K.; Furui, S. Gadolinium-based contrast agent accumulates in the brain even in subjects without severe renal dysfunction: Evaluation of autopsy brain specimens with inductively coupled plasma mass spectroscopy. Radiology 2015, 276, 228-232. [CrossRef] [PubMed]

6. Gulani, V.; Calamante, F.; Shellock, F.G.; Kanal, E.; Reeder, S.B. Gadolinium deposition in the brain: Summary of evidence and recommendations. Lancet Neurol. 2017, 16, 564-570. [CrossRef]

7. Thomsen, H.S.; Morcos, S.K.; Almen, T.; Bellin, M.F.; Bertolotto, M.; Bongartz, G.; Clement, O.; Leander, P.; Heinz-Peer, G.; Reimer, P.; et al. Nephrogenic systemic fibrosis and gadolinium-based contrastmedia: Updated ESUR contrast medium safety committee guidelines. Eur. Radiol. 2013, 23, 307-318. [CrossRef] [PubMed] 
8. Fraum, T.J.; Ludwig, D.R.; Bashir, M.R.; Fowler, K.J. Gadolinium-based contrast agents: A comprehensive risk assessment. J. Magn. Reson. Imaging 2017, 46, 338-353. [CrossRef] [PubMed]

9. Afzal, V.; Brasch, R.C.; Nitecki, D.E.; Wolff, S. Nitroxyl spin label contrast enhancers for magnetic resonance imaging studies of acute toxicity and mutagenesis. Investig. Radiol. 1984, 19, 549-552. [CrossRef]

10. Keana, J.F.W.; Pou, S.; Rosen, G.M. Nitroxides as potential contrast enhancing agents for MRI application: Influence of structure on the rate of reduction by rat hepatocytes, whole liver homogenate, subcellular fractions, and ascorbate. Magn. Reson. Med. 1987, 3, 83-88. [CrossRef]

11. Saphier, O.; Silberstein, T.; Shames, A.I.; Likhtenshtein, G.I.; Maimon, E.; Mankuta, D.; Mazor, M.; Katz, M.; Meyerstein, D.; Meyerstein, N. The reduction of a nitroxide spin label as a probe of human blood antioxidant properties. Free Radic. Res. 2003, 37, 301-308. [CrossRef]

12. Zhuang, X.; Xiao, C.; Oyaizu, K.; Chikushi, N.; Chen, X.; Nishide, H. Synthesis of amphiphilic block copolymers bearing stable nitroxyl radicals. J. Polym. Sci. Part A Polym. Chem. 2010, 48, 5404-5414. [CrossRef]

13. Dobrynin, S.A.; Glazachev, Y.I.; Gatilov, Y.V.; Chernyak, E.I.; Salnikov, G.E.; Kirilyuk, I.A. Synthesis of 3,4-bis(hydroxymethyl)-2,2,5,5-tetraethylpyrrolidin-1-oxyl via 1,3-dipolar cycloaddition of azomethine ylide to activated alkene. J. Org. Chem. 2018, 83, 5392-5397. [CrossRef] [PubMed]

14. Yoshitomi, T.; Mikyamoto, D.; Nagasaki, Y. Design of core-shell-type nanoparticles carrying stable radicals in the core. Biomacromolecules 2009, 10, 596-601. [CrossRef] [PubMed]

15. Marx, L.; Chiarelli, R.; Guiberteau, T.; Rassat, A. A comparative study of the reduction by ascorbate of 1,1,3,3-tetraethylisoindolin-2-yloxyl and of 1,1,3,3-tetramethylisoindolin-2-yloxyl. J. Chem. Soc. Perkin Trans. 1 2000, 1181-1182. [CrossRef]

16. Paletta, J.T.; Pink, M.; Foley, B.; Rajca, S.; Rajca, A. Synthesis and reduction kinetics of sterically shielded pyrrolidine nitroxides. Org. Lett. 2012, 14, 5322-5325. [CrossRef] [PubMed]

17. Kirilyuk, I.A.; Bobko, A.A.; Semenov, S.V.; Komarov, D.A.; Irtegova, I.G.; Grigor'ev, I.A.; Bagryanskaya, E. Effect of sterical shielding on the redox properties of imidazoline and imidazolidine nitroxides. J. Org. Chem. 2015, 80, 9118-9125. [CrossRef]

18. Nagura, K.; Takemoto, Y.; Moronaga, S.; Uchida, Y.; Shimono, S.; Shiino, A.; Tanigaki, K.; Amano, T.; Yoshino, F.; Noda, Y.; et al. Preparation of robust metal-free magnetic nanoemulsions encapsulating low-molecular-weight nitroxide radicals and hydrophobic drugs directed toward MRI-visible targeted delivery. Chem. Eur. J. 2017, 23, 15713-15720. [CrossRef]

19. Nagura, K.; Bogdanov, A.; Chumakova, N.; Vorobiev, A.K.; Moronaga, S.; Imai, H.; Matsuda, T.; Noda, Y.; Maeda, T.; Koizumi, S.; et al. Size-tunable MRI-visible nitroxide-based magnetic mixed micelles: Preparation, stability and theranostic application. Submitted for publication.

20. Jiang, X.; Xin, H.; Ren, Q.; Gu, J.; Zhu, L.; Du, F.; Feng, C.; Xie, Y.; Sha, X.; Fang, X. Nanoparticles of 2-deoxy-D-glucose functionalized poly(ethyleneglycol)-co-poly(trimethylene carbonate) for dual-targeted drug delivery in glioma treatment. Biomaterials 2014, 35, 518-529. [CrossRef]

21. Xiong, F.; Xiong, C.; Hua, X.; Shan, X.; Zhang, Y.; Gu, N. Preparation, characterization of 2-deoxy-D-glucose functionalized dimercaptosuccinic acid-coated maghemite nanoparticles for targeting tumor cells. Pham. Res. 2012, 29, 1087-1097. [CrossRef]

22. Ranjbar-Navazi, Z.; Eskandani, M.; Johari-Ahar, M.; Nemati, A.; Akbari, H.; Davaran, S.; Omidi, Y. Doxorubicin-conjugated D-glucosamine- and folate- bi-functionalised $\mathrm{InP} / \mathrm{ZnS}$ quantum dots for cancer cells imaging and therapy. J. Drug Target. 2018, 3, 267-277. [CrossRef]

23. Korotcov, A.V.; Ye, Y.; Chen, Y.; Zhang, F.; Huang, S.; Lin, S.; Sridhar, R.; Achilefu, S.; Wang, P.C. Glucosamine-linked near-infrared fluorescent probes for imaging of solid tumor xenografts. Mol. Imaging Biol. 2012, 14, 443-451. [CrossRef] [PubMed]

24. Uchida, Y.; Uematsu, T.; Nakayama, Y.; Takahashi, H.; Tsue, H.; Tanaka, K.; Tamura, R. Partial resolution of racemic trans-4-[5-(4-alkoxyphenyl)-2,5-dimethylpyrrolidine-1-oxyl-2-yl]benzoic acids by the diastereomer method with (R)- or (S)-1-phenylethylamine. Chirality 2008, 20, 282-287. [CrossRef] [PubMed]

25. Uchida, Y.; Tamura, R.; Ikuma, N.; Shimono, S.; Yamauchi, J.; Aoki, Y.; Nohira, H. Synthesis and characterization of novel all-organic liquid crystalline radicals. Mol. Cryst. Liq. Cryst. 2007, 479, 1251-1259. [CrossRef]

26. Zhang, Q.; Lebl, T.; Kulczynska, A.; Botting, N.P. The synthesis of novel hexa- ${ }^{13}$ C-labelled glucosinolates from $\left[{ }^{13} C_{6}\right]$-D-glucose. Tetrahedron 2009, 65, 4781-4876. [CrossRef] 
27. Soli, E.D.; Manoso, A.S.; Patterson, M.C.; DeShong, P. Azide and cyanide displacements via hypervalent silicate intermediates. J. Org. Chem. 1999, 64, 3171-3177. [CrossRef] [PubMed]

28. Muhizi, T.; Grelier, S.; Coma, V. Synthesis and antibacterial activity of aminodeoxyglucose derivatives against Listeria innocua and Salmonella typhimurium. J. Agric. Food Chem. 2009, 57, 8770-8775. [CrossRef] [PubMed]

29. Livramento, J.B.; Tóth, E.; Sour, A.; Borel, A.; Merbach, A.E.; Ruloff, R. High Relaxivity confined to a small molecular space: A metallostar-based, potential MRI contrast agent. Angew. Chem. Int. Ed. 2005, 44, 1480-1484. [CrossRef]

30. Caravan, P.; Farrar, C.T.; Frullano, L.; Uppal, R. Influence of molecular parameters and increasing magnetic field strength on relaxivity of gadolinium- and manganese-based $\mathrm{T}_{1}$ contrast agents. Contrast Media Mol. Imaging 2009, 4, 89-100. [CrossRef]

31. De Sousa, P.L.; Livramento, J.B.; Helm, L.; Merbach, A.E.; Meme, W.; Doan, B.T.; Beloeil, J.C.; Prata, M.I.; Santos, A.C.; Geraldes, C.F.; et al. In vivo MRI assessment of a novel Gd ${ }^{\mathrm{III}}$-based contrast agent designed for high magnetic field applications. Contrast Media Mol. Imaging 2008, 3, 78-85. [CrossRef]

32. European Food Safety Authority (EFSA). Opinion of the scientific panel on dietetic products, nutrition and allergies on a request from the commission related to the tolerable upper intake level of vitamin $\mathrm{C}$ (L-Ascorbic acid, its calcium, potassium and sodium salts and L-Ascorbyl-6-palmitate). EFSA J. 2004, 59, $1-21$.

33. Hyodo, F.; Matsumoto, K.; Matsumoto, A.; Mitchell, J.B.; Krishna, M.C. Probing the intracellular redox status of tumors with magnetic resonance imaging and redox-sensitive contrast agents. Cancer Res. 2006, 66, 9921-9928. [CrossRef] [PubMed]

34. Hyodo, F.; Chuang, K.H.; Goloshevsky, A.G.; Sulima, A.; Griffiths, G.L.; Mitchell, J.B.; Koretsky, A.P.; Krishna, M.C. Brain redox imaging using blood-brain barrier permeable nitroxide MRI contrast agent. J. Cereb. Blood Flow Metab. 2008, 28, 1165-1174. [CrossRef]

35. Emoto, M.C.; Yamada, K.; Yamato, M.; Fujii, H.G. Novel ascorbic acid-resistive nitroxide in a lipid emulsion: An efficient brain imaging contrast agent for MRI of small rodents. Neurosci. Lett. 2013, 546, 11-15. [CrossRef] [PubMed]

36. Yamasaki, T.; Mito, F.; Matsuoka, Y.; Yamato, M.; Yamada, K. Nitroxides-Theory, Experiment and Applications; Kokorin, A.I., Ed.; INTECH: Rijeka, Croatia, 2012; Chapter 8.

37. Ma, Y.; Huang, J.; Song, S.; Chen, H.; Zhang, Z. Cancer-targeted nanotheranostics: Recent advances and perspectives. Small 2016, 12, 4936-4954. [CrossRef] [PubMed]

38. Sumer, B.; Gao, J. Theranostic nanomedicine for cancer. Nanomedicine 2008, 3, 137-140. [CrossRef] [PubMed]

39. Movassaghian, S.; Merkel, O.M.; Torchilin, V.P. Applications of polymer micelles for imaging and drug delivery. Wiley Interdiscip. Rev. Nanomed. Nanobiotechnol. 2015, 7, 691-707. [CrossRef] [PubMed] 